\title{
SIMULAÇÃO COMPUTACIONAL DE PILARES DE AÇO SUBMETIDOS À COMPRESSÃO AXIAL
}

\section{Computational simulation of steel columns submitted to axial compression}

\author{
Leonardo Carvalho MESQUITA ${ }^{1}$, Arthur Filipe Freire GOMES $^{2}$, Filipe Silveira LEÃO ${ }^{3}$
}

Recebido em 22 de janeiro de 2019; aceito em 28 de julho de 2019; disponível on-line em 03 de junho de 2020.

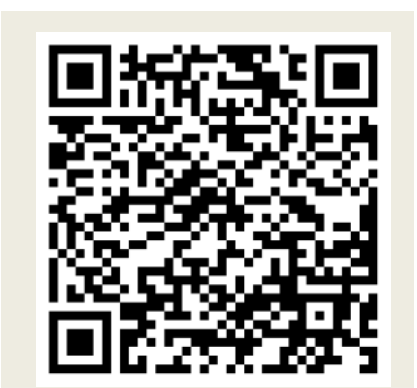

PALAVRAS CHAVE:

Pilares de aço; Imperfeições geométricas; Tensões residuais; Análise computacional; Método dos elementos finitos;

\section{KEYWORDS:}

Steel columns;

Geometric imperfections; Residual stress;

Computational analysis;

Finite element method.

\footnotetext{
* Contato com os autores:
}

${ }^{1}$ e-mail: leonardo.mesquita@ufv.br (L.C. Mesquita)

Engenheiro Civil, Mestre em Engenharia Civil (Estruturas), Professor Assistente da Universidade Federal de Viçosa

2e-mail: arthurfreire2009@gmail.com (A. F. F. Gomes)

Mestrando na Universidade Federal de São Carlos, Engenheiro Civil, Professor Substituto da Universidade Federal de Viçosa

${ }^{3}$ e-mail: filipe.leao@ufv.br (F. S. Leão)

Engenheiro Civil pela Universidade Federal de Viçosa
ABSTRACT: This research aimed to simulate the structural behavior of steel columns subjected to axial compression and to evaluate the influence of geometric and material imperfections (residual stresses) on the strength of these elements. In order to achieve is aim, finite element computational models were developed using Abaqus, which were analysis (Static Ricks). The results obtained were compared with the results presented by the elastic buckling equation proposed by Euler and the buckling curve prescribed by ABNT NBR 8800: 2008. In general, the results obtained were very close if compared to the reference values. It indicates that the computational models were able to simulate the structural behavior of a real pillar and that the proposed methodology is valid. When analyzing the influence of the geometric imperfections, it was observed that the models with imperfections of $L / 1000$ and $L / 1500$ were the ones that most approached the expected results. In the case of material imperfections, the models with $10 \%$ and $15 \%$ of residual stresses were the ones that presented the best results. In this way, the adopted strategies may contribute to future research related to the structural behavior of columns and buckling. 


\section{INTRODUÇÃO}

Pilares são elementos estruturais responsáveis por transferir as cargas das lajes e vigas até as fundações e, em geral, são solicitados por uma força axial de compressão. Em função de sua esbeltez, relação entre o comprimento e o raio de giração, o pilar pode entrar em colapso por compressão ou flambagem (instabilidade).

No caso de pilares de aço, a capacidade resistente deste elemento estrutural é influenciada por sua esbeltez, pelas imperfeições geométricas e de material. Esta última é caracterizada pela distribuição e intensidade das tensões residuais, oriundas do processo de fabricação do elemento estrutural e que são difíceis de serem determinadas experimentalmente.

Em geral, para se conhecer e estudar o comportamento de pilares são realizados ensaios em protótipos reais, que são difíceis de serem executados e requerem uma estrutura com equipamentos específicos o que, em muitos casos, inviabiliza a realização destes testes. Desta forma, as simulações computacionais surgem como uma alternativa atrativa uma vez que, um modelo computacional calibrado pode simular o comportamento de diversos pilares com diferentes parâmetros, a um custo relativamente baixo.

Portanto, este trabalho visa contribuir com outras pesquisas ao apresentar uma metodologia para criação de modelos computacionais de elementos finitos que consigam simular o comportamento estrutural de pilares de aço, bem como mostrar a influência das imperfeições geométricas e de materiais sobre a capacidade resistente destes elementos estruturais.

\section{OBJETIVOS}

Este trabalho tem como objetivo simular computacionalmente o comportamento estrutural de pilares de aço submetidos à compressão axial, com ênfase na influência das imperfeições geométricas e de material (tensões residuais).

\section{REFERENCIAL TEÓRICO}

Nos itens a seguir são apresentados conceitos importantes para a compressão do comportamento estrutural de pilares de aço e, consequentemente, para a simulação computacional destes elementos.

\subsection{CARGA CRÍTICA DE FLAMBAGEM ELÁSTICA}

Euler, no ano de 1774 , foi o primeiro pesquisador a estudar a relação entre flambagem e a redução da capacidade resistente de uma barra submetida à compressão axial (Figura 1) (TIMOSHENKO e GERE, 1961; HIBBELER, 2010). Em seus estudos, Euler assumiu as seguintes hipóteses:

i. Barra perfeitamente reta, isto é, isenta de imperfeições geométricas;

ii. Elemento solicitado apenas por uma força axial de compressão com intensidade constante;

iii. Força axial de compressão com direção constante durante a flambagem da barra;

iv. A flambagem ocorre por flexão pura;

v. Material homogêneo, elástico, resistência infinita e isento de tensões residuais.
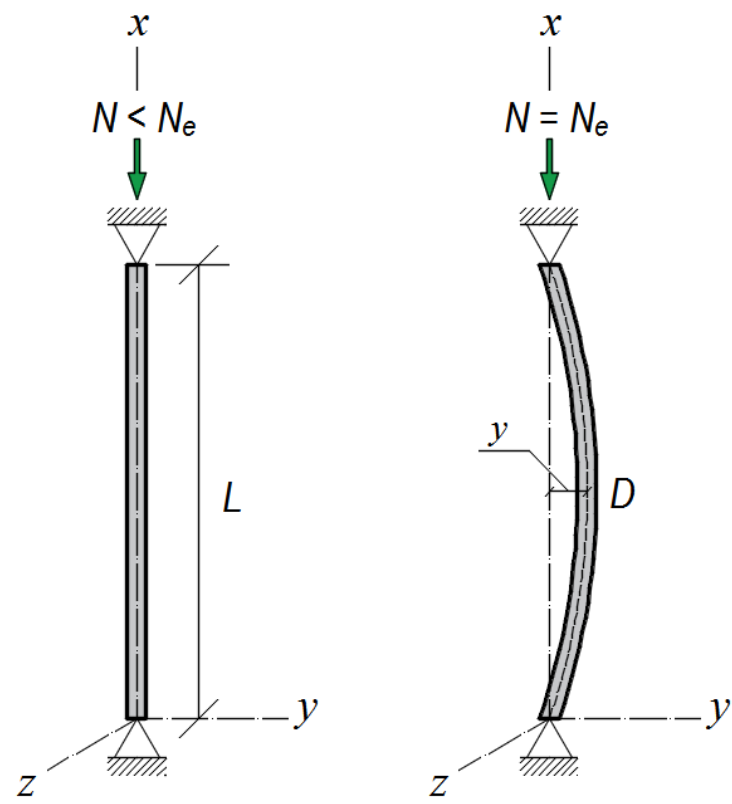

FIGURA 1: Barra birrotulada submetida à compressão axial. 
A partir dos conceitos da resistência dos materiais tem-se:

$$
\frac{\mathrm{M}}{\mathrm{E} \cdot \mathrm{I}_{\mathrm{z}}}=\frac{1}{\mathrm{R}}
$$

Em que:

$\mathbf{M}=$ momento fletor em um ponto $\mathrm{D}$ qualquer, igual ao produto entre a força axial $\mathbf{N}$ e a excentricidade $\mathbf{y}$;

$\mathbf{E}=$ é o módulo de elasticidade do material utilizado para fabricar a barra;

$\mathbf{I}_{\mathbf{z}}=$ é o momento de inércia da seção transversal em relação ao eixo z-z;

$1 / R$ = é a curvatura da barra analisada.

A curvatura aproximada da barra é definida por:

$$
\frac{1}{R}=\frac{-d^{2} y}{d x^{2}}
$$

Igualando as Equações [1] e [2] e substituído o valor do momento fletor $\mathbf{M}$ pelo produto entre a força axial $\mathbf{N}$ e a excentricidade $\mathbf{y}$, tem-se:

$$
\frac{N \cdot y}{E \cdot I_{z}}=\frac{-d^{2} y}{d x^{2}}
$$

$$
\text { Fazendo } \mathrm{p}=\sqrt{\frac{\mathrm{N}}{\mathrm{E} \cdot \mathrm{I}_{\mathrm{z}}}}, \text { a equação acima }
$$

pode ser escrita como:

$$
y^{\prime \prime}+p^{2} y=0
$$

Resolvendo essa equação diferencial chega-se:

$$
\mathrm{y}=\mathrm{A} \cdot \sin (\mathrm{px})+\mathrm{B} \cdot \cos (\mathrm{px}) \quad \text { Eq. [5] }
$$

Sendo:

$\mathbf{A}$ e $\mathbf{B}=$ constantes reais.

Aplicando as condições de contorno temse: $\quad \mathrm{x}=0 \rightarrow \mathrm{y}=0 \quad$ (Condição $\quad 1$ ); $\mathrm{e}$ $\mathrm{x}=\mathrm{L} \rightarrow \mathrm{y}=0 \quad$ (Condição 2$). \quad$ A partir da "Condição 1" nota-se que a constante B da Equação [5] é nula. Por meio da "Condição 2" nota-se que o termo $\mathrm{A} \cdot \sin (\mathrm{px})$ é igual a zero, isto é, $\mathrm{px}=\mathrm{n} \pi$, com $\mathrm{n}=1,2,3, \ldots$ Desta forma, chega-se a Equação 6, proposta por Euler, que permite calcular a carga crítica de flambagem elástica para uma barra birrotulada.

$$
\mathrm{N}_{\mathrm{e}}=\mathrm{E} \cdot \mathrm{I}_{\mathrm{z}}\left(\frac{\mathrm{n} \pi}{\mathrm{L}}\right)^{2} \quad \text { Eq. [6] }
$$

Nesta Equação a variável $\mathbf{n}$, conhecida como autovetor, define o formato da barra (números de curvaturas) após a ocorrência do fenômeno de flambagem. $\mathbf{O}$ valor de $\mathbf{n}=\mathbf{0}$ não interessa, tendo em vista que nesse caso a barra permanecerá reta. Com $\mathbf{n}=1$ tem-se o primeiro modo de flambagem, que é o modo menor energia. Os outros autovetores $(2,3,4, \ldots)$ não apresentam aplicação prática, uma vez que são modos de flambagem que necessitam de maior energia para acontecer, o que não ocorrerá na prática (QUEIROZ, 1986).

\subsection{IMPERFEIÇÕES GEOMÉTRICAS INICIAIS}

Em geral, os pilares de aço não são perfeitamente retos, isto é, possuem uma curvatura inicial e pequenas imperfeições que irão favorecer a ocorrência do fenômeno de flambagem. Segundo Fakury, Silva e Caldas (2016), o comportamento estrutural das barras de eixo reto difere do comportamento estrutural das barras com curvatura inicial e, desta forma, a "hipótese i" proposta por Euler não se aplica nesses casos. Ainda de acordo com Fakury, Silva e Caldas (2016) e Galambos (1998), as barras de eixo reto permanecem indeformáveis, até que a força axial de compressão atinja o valor da carga crítica de flambagem elástica (Reta A-B da Figura 2). Por outro lado, as barras com curvatura inicial $\left(\Delta_{\mathrm{i}}\right)$ têm o deslocamento lateral (excentricidade $\mathbf{y}$ da Figura 1) continuamente aumentado, à medida que a força axial de compressão se eleva, até o momento em que a barra se torna instável, o que caracteriza o fenômeno de flambagem (Curva C-B da Figura 2). 

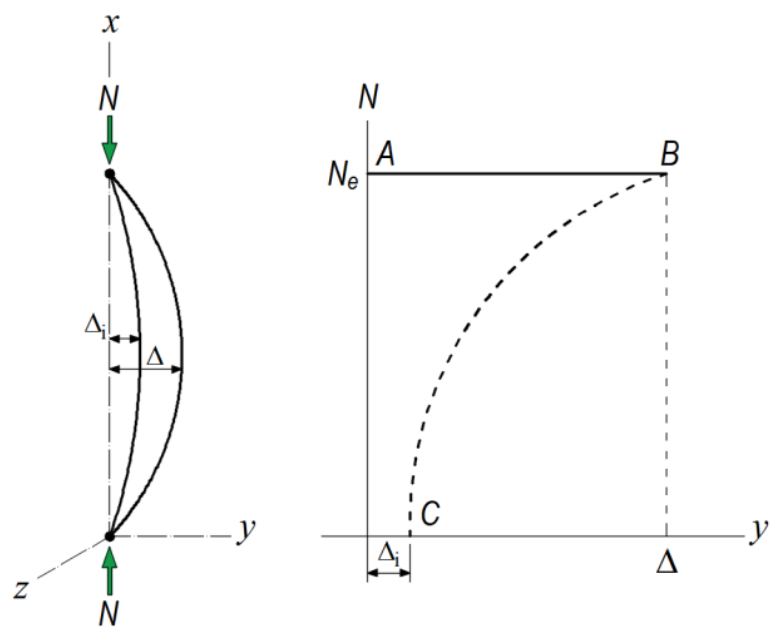

FIGURA 2: Curva força axial de compressão $\times$ deslocamento lateral para uma barra perfeitamente reta (linha contínua) e para uma barra com curvatura inicial $\Delta_{\text {i }}$ (linha tracejada).

FONTE: Galambos (1998).

A NBR 8800 (ABNT, 2008) prescreve que as imperfeições geométricas iniciais devem ser tomadas na forma de uma imperfeição equivalente global igual a L/500 ou local igual a $\mathrm{L} / 1000$, onde $\mathrm{L}$ é o comprimento destravado do elemento estrutural analisado.

\subsection{TENSÕES RESIDUAIS}

As tensões residuais surgem nos elementos estruturais de aço em função do resfriamento não-uniforme destes elementos, decorrentes dos processos de laminação a quente, oxicorte, soldagem e etc. De acordo com Galambos (1998), a distribuição e intensidade das tensões residuais dependem das dimensões e do formato da seção transversal, dos métodos de retificação das peças, das propriedades mecânicas e térmicas do material, da temperatura de laminação ou soldagem e da velocidade de resfriamento da peça.

A capacidade resistente dos pilares de aço depende diretamente da magnitude das tensões residuais existentes na peça, uma vez que essas tensões podem provocar o escoamento ou a flambagem prematura deste elemento estrutural. Assim, quanto maior for a intensidade das tensões residuais de compressão menor será a capacidade resistente do elemento solicitado à compressão (FAKURY, 2009).

Para considerar o efeito das tensões residuais em modelos computacionais de elementos finitos, alguns autores, entre eles Pfeil e Pfeil (2009), Almeida (2012), Dutra (2014) e Cardoso (2014), propõem modificar o diagrama tensão $\times$ deformação que descreve 0 comportamento mecânico do aço (Figura 3), de modo que o escoamento do aço, quando solicitado à tração ou à compressão, comece em um valor de tensão $\sigma_{\mathfrak{p}}$, dada por:

$$
\sigma_{\mathrm{p}}=\mathrm{f}_{\mathrm{y}}-\sigma_{\mathrm{r}}
$$

Em que:

$\sigma_{\mathrm{p}}=$ é a tensão correspondente ao limite de proporcionalidade do aço;

$\mathbf{f}_{\mathrm{y}}=$ é a resistência ao escoamento do aço;

$\sigma_{r}=$ é a tensão residual média no elemento estrutural.

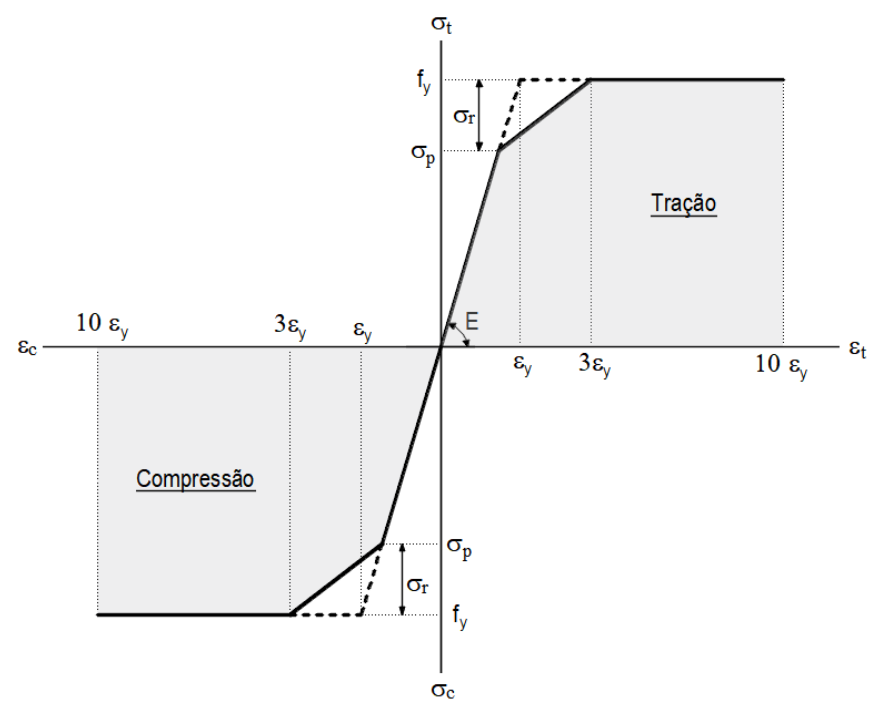

FIGURA 3: Curva tensão $\times$ deformação utilizada para descrever o comportamento mecânico do aço considerando as tensões residuais. FONTE: Adaptado de Almeida (2012). 


\subsection{CURVA DE FLAMBAGEM PRESCRITA PELA NBR 8800 (ABNT, 2008)}

Conforme discutido no Item 3.1, a Equação [6] permite obter o valor da carga crítica de flambagem elástica. Entretanto, como visto nos Itens 3.2 e 3.3, as hipóteses $i$ e $v$ definidas por Euler não são aplicáveis aos elementos estruturais de aço, uma vez que estes elementos possuem imperfeições geométricas iniciais e tensões residuais. Em função disso, a NBR 8800 (ABNT, 2008) prescreve a utilização de uma curva única de flambagem, definida em função dos parâmetros adimensionais $\chi$, chamado de fator de redução associado à resistência à compressão, e $\lambda_{0}$, chamado de índice de esbeltez reduzido (Figura 4).

Segundo Fakury (2009), a capacidade resistente à compressão de um pilar de aço depende, além da imperfeição geométrica inicial e da distribuição e intensidade das tensões residuais, da esbeltez do elemento e da resistência ao escoamento do aço. No entanto, como as tensões residuais variam de elemento estrutural para elemento estrutural a rigor são obtidas diversas curvas de flambagem. A NBR 8800 (ABNT, 2008), para simplificar o processo de cálculo, adota uma curva única que conduz a resultados superiores aos reais, em algumas situações, e inferiores, em outras situações, mas em ambos os casos dentro de limites considerados aceitáveis em termos de segurança estrutural.

\section{PROCEDIMENTOS PARA ANÁLISE COMPUTACIONAL}

\subsection{DESENVOLVIMENTO DOS MODELOS DE ELEMENTOS FINITOS}

Para simular o comportamento estrutural de pilares de aço submetidos à compressão axial foram desenvolvidos modelos computacionais de elementos finitos, com o auxílio do software comercial Abaqus (DASSAULT SYSTÈMES, 2012), seguindo os passos mostrados na Figura 5.

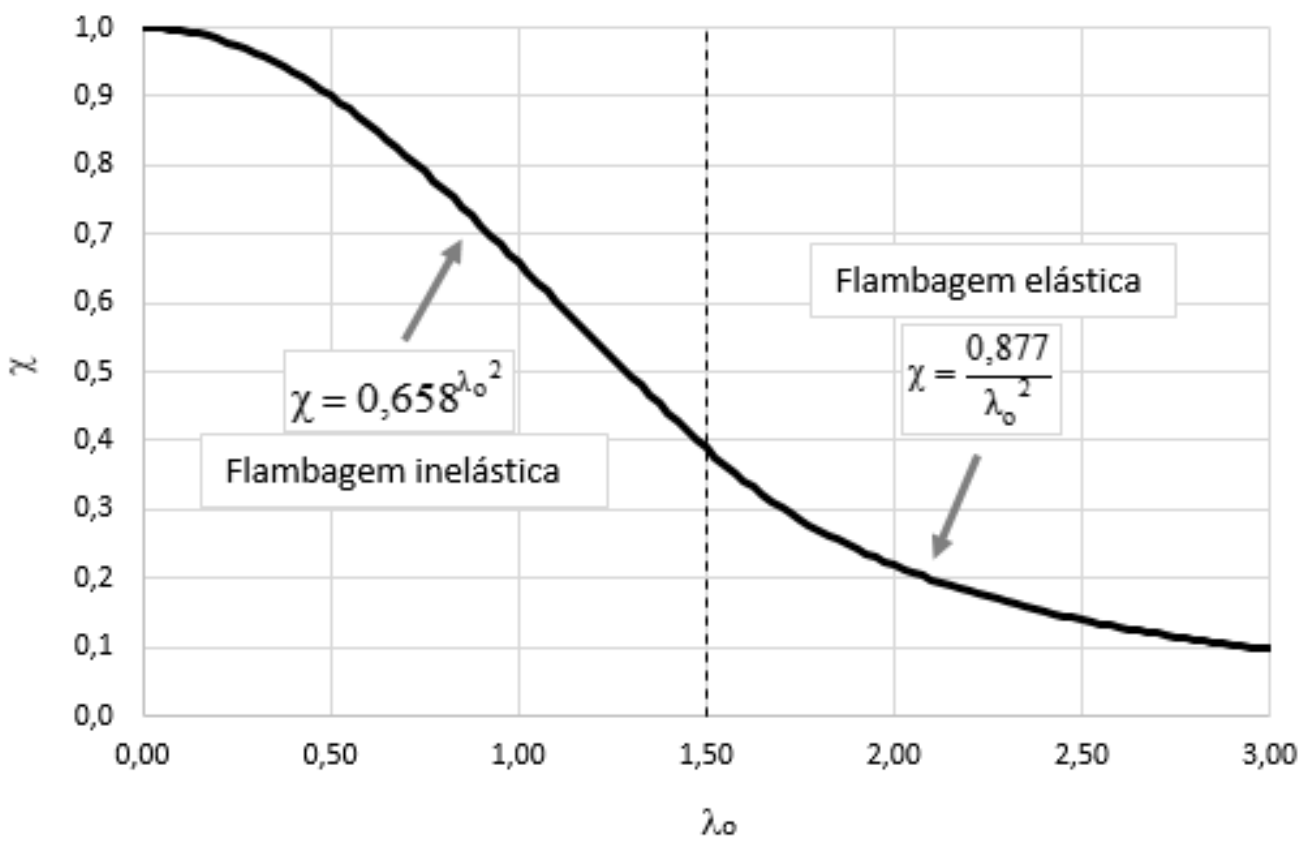

FIGURA 4: Curva única de flambagem prescrita. FONTE: NBR 8800 (ABNT, 2008). 


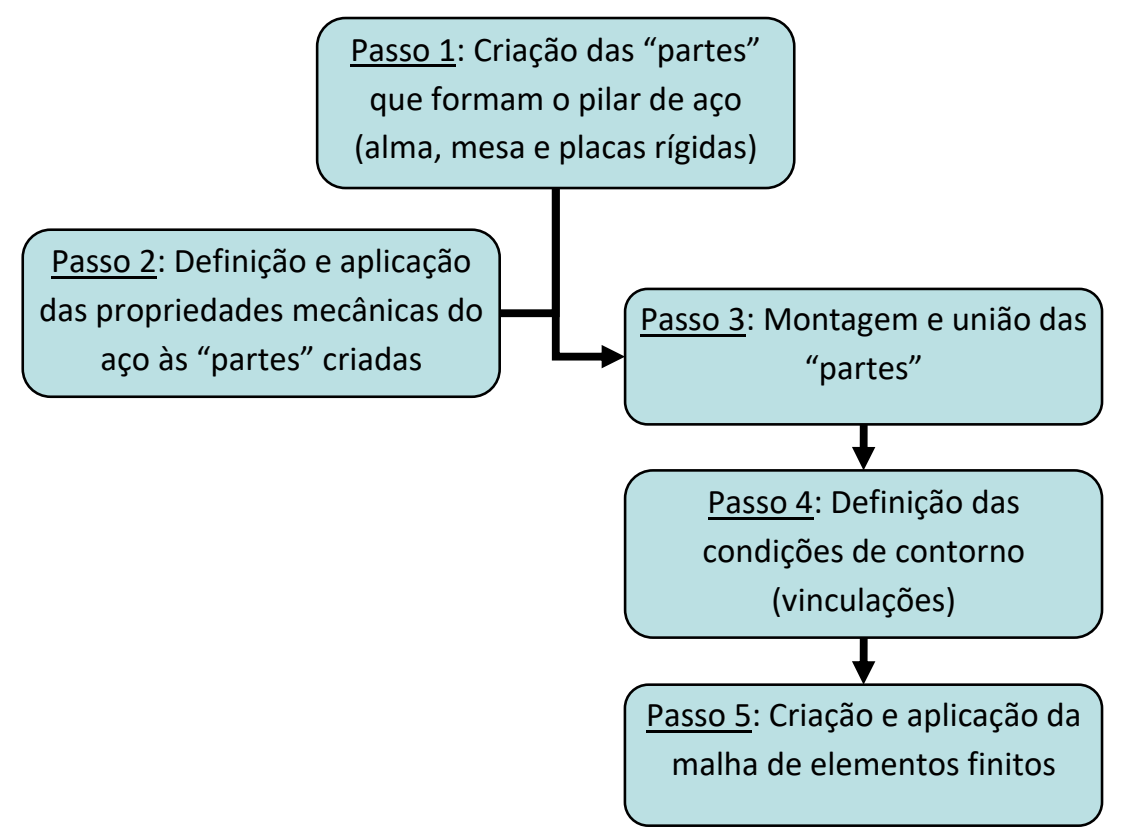

FIGURA 5: Sequência utilizada para o desenvolvimento dos modelos computacionais de elementos finitos. FONTE: Autores.

Para simular a condição birrotulada proposta por Euler utilizaram-se duas placas rígidas colocadas nas extremidades do modelo. Nestas placas foram criados pontos de referência ("Sup" e "Inf") aos quais foram atribuídas as condições de contorno (Figura 6). Por fim, elas foram conectadas ao restante do modelo pilar por meio de uma restrição (Constraints) do tipo Tie, que restringe qualquer deslocamento relativo entre a placa rígida e o pilar.

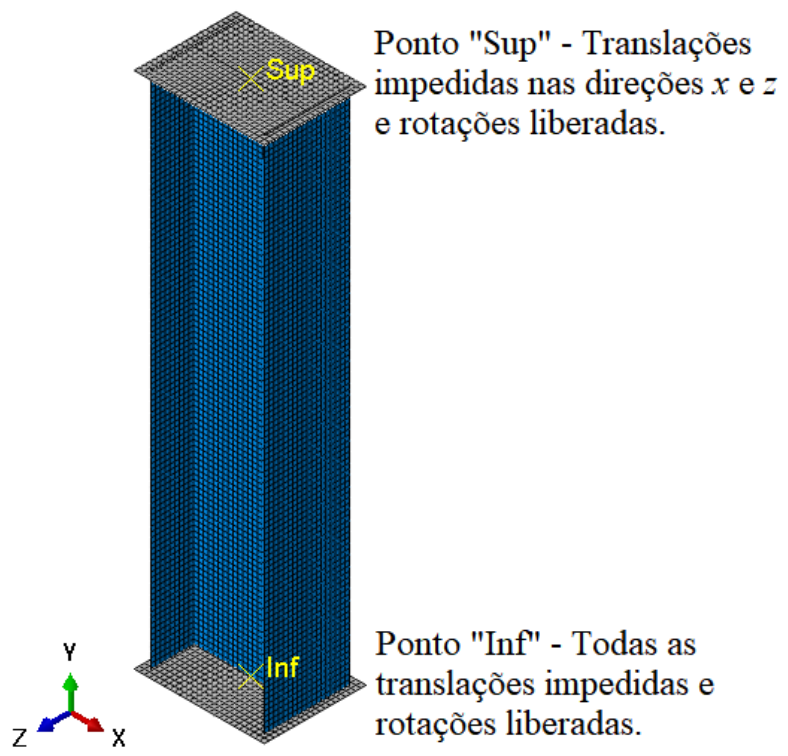

(a)

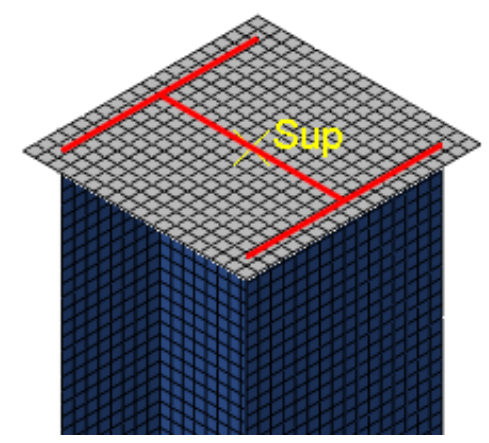

(b)

FIGURA 6: (a) Condições de contorno utilizadas no modelo; (b) detalhe da placa rígida colocada na extremidade superior do pilar, em vermelho a região onde foi utilizada a restrição do tipo Tie.

FONTE: Autores. 
Em todos os modelos desenvolvidos utilizaram-se elementos de casca (Shell) do tipo S4, elementos planos com quatro nós e três graus de liberdade por nó, para discretizar o perfil estrutural e elementos rígidos (Rigid) do tipo R3D4 para discretizar as placas rígidas. Após realizar um estudo de refinamento de malha optou-se por utilizar elementos finitos com tamanho máximo de 15 milímetros.

\subsection{COMPORTAMENTO MECÂNICO DO AÇO}

Para simular o comportamento mecânico do aço estrutural utilizaram-se os modelos constitutivos Elasticity e Plasticity disponível no software Abaqus (DASSAULT SYSTÈMES, 2012), ao quais foi informado o diagrama tensão $\times$ deformação apresentado na Figura 3, que considera a influência das tensões residuais. Além disso, para todos os modelos empregou-se um aço do tipo ASTM A572 Grau 50, que possui $345 \mathrm{MPa}$ de resistência ao escoamento.

\subsection{ANÁLISE DE FLAMBAGEM E ANÁLISE NÃO- LINEAR PLÁSTICA}

Os modelos desenvolvidos foram analisados em duas etapas, a primeira referente a uma análise de flambagem elástica (Buckle) e a segunda a uma análise não-linear plástica (Static Riks), conforme a sequência apresentada na Figura 7.

Ao realizar a análise de flambagem elástica o software Abaqus apresenta as configurações deformadas do pilar (autovetores), com o deslocamento horizontal máximo igual a um (Figura 8). Assim, as imperfeições geométricas foram introduzidas no modelo computacional considerando-se o deslocamento horizontal do primeiro autovetor (primeiro modo de flambagem) multiplicado por um fator representativo da imperfeição como, por exemplo, L/1000. Desta maneira, ao realizar a análise não-linear plástica o modelo computacional possui uma curvatura inicial semelhante ao primeiro autovetor, cujo deslocamento horizontal máximo é igual ao valor da imperfeição.

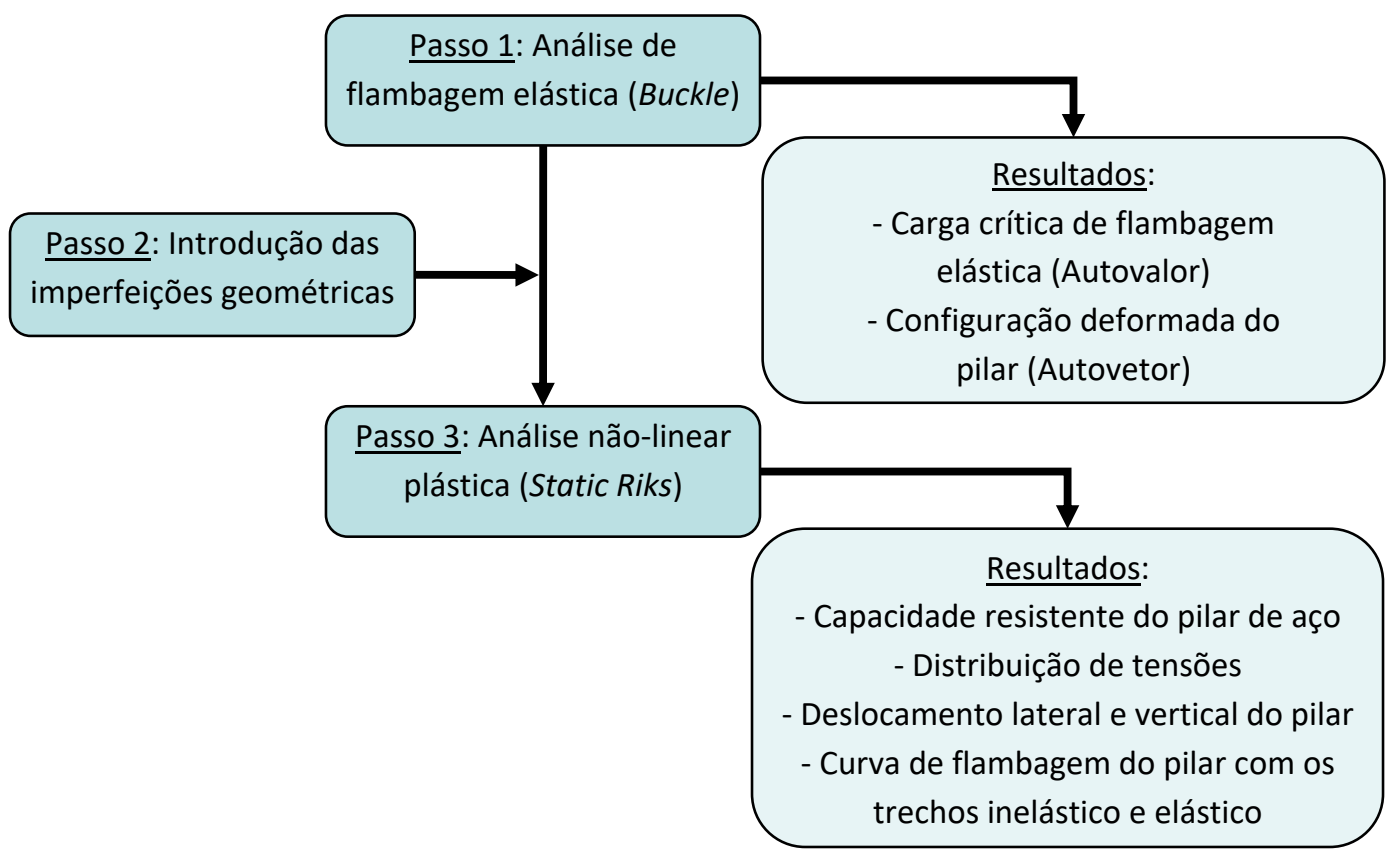

FIGURA 7: Sequência utilizada para a análise computacional dos modelos de elementos finitos desenvolvidos. 


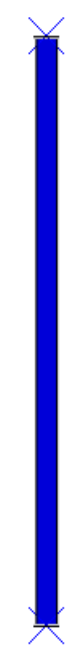

(a) pilar na posição indeformada

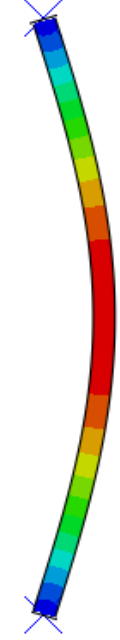

(b) primeiro modo de flambagem
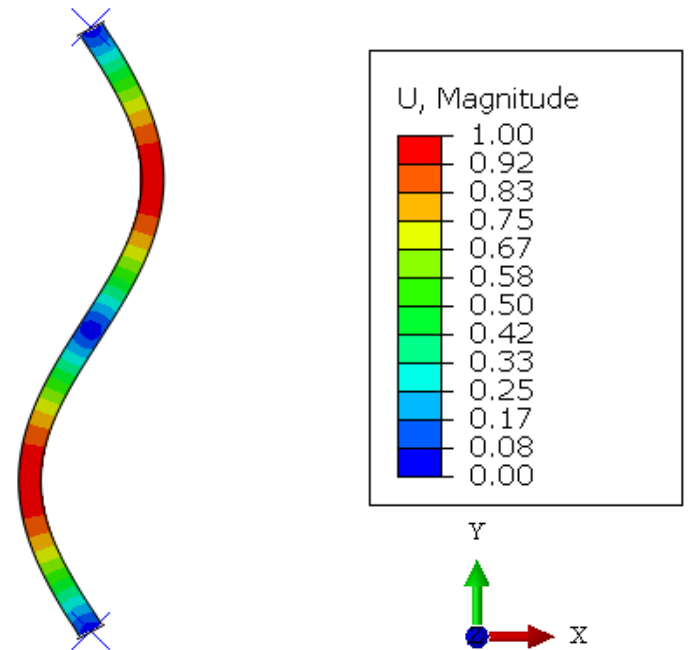

FIGURA 8: Configuração deformada do pilar obtida após a análise de flambagem elástica.

FONTE: Autores.

\subsection{PILARES ANALISADOS}

Para simular o comportamento estrutural de pilares de aço submetidos à compressão axial e avaliar a influência das imperfeições geométricas e das tensões residuais sobre a capacidade resistente destes pilares, utilizou-se um perfil laminado do tipo W $250 \times$ 73,0 (H). Esse perfil é comumente utilizado em pilares e é isento de problemas de instabilidade local.

A fim de obter as curvas de flambagem do pilar de aço, em função da imperfeição geométrica inicial e da intensidade das tensões residuais adotada, realizou-se a análise de modelos com os seguintes valores de esbeltez $(\lambda)$ : $45,60,75,90,105,120,135$ e 150 . A relação dos modelos analisados, com seus respectivos valores de imperfeição geométrica e tensões residuais, é apresentada na Tabela 1.

TABELA 1: Relação dos modelos de elementos finitos analisados.

\begin{tabular}{|c|c|c|c|}
\hline Modelo ${ }^{1}$ & Eixo $^{2}$ & Tensão Residual ${ }^{3}$ & Imperf. Geomét. ${ }^{4}$ \\
\hline$M-\lambda-X-0-L / 1000$ & $x-x$ & $0 \%$ & $\mathrm{~L} / 1000$ \\
\hline$M-\lambda-X-10-L / 1000$ & $x-x$ & $10 \%$ & $\mathrm{~L} / 1000$ \\
\hline$M-\lambda-X-15-L / 1000$ & $x-x$ & $15 \%$ & $\mathrm{~L} / 1000$ \\
\hline$M-\lambda-X-20-L / 1000$ & $x-x$ & $20 \%$ & $\mathrm{~L} / 1000$ \\
\hline$M-\lambda-X-30-L / 1000$ & $x-x$ & $30 \%$ & $\mathrm{~L} / 1000$ \\
\hline$M-\lambda-X-40-L / 1000$ & $x-x$ & $40 \%$ & $\mathrm{~L} / 1000$ \\
\hline$M-\lambda-Y-0-L / 1000$ & $y-y$ & $0 \%$ & $\mathrm{~L} / 1000$ \\
\hline$M-\lambda-Y-10-L / 1000$ & $y-y$ & $10 \%$ & $\mathrm{~L} / 1000$ \\
\hline$M-\lambda-Y-15-L / 1000$ & $y-y$ & $15 \%$ & $\mathrm{~L} / 1000$ \\
\hline$M-\lambda-Y-20-L / 1000$ & $y-y$ & $20 \%$ & $\mathrm{~L} / 1000$ \\
\hline$M-\lambda-Y-30-L / 1000$ & $y-y$ & $30 \%$ & L/1000 \\
\hline$M-\lambda-Y-40-L / 1000$ & $y-y$ & $40 \%$ & $\mathrm{~L} / 1000$ \\
\hline$M-\lambda-X-15-L / 250$ & $x-x$ & $15 \%$ & $\mathrm{~L} / 250$ \\
\hline$M-\lambda-X-15-L / 500$ & $x-x$ & $15 \%$ & $\mathrm{~L} / 500$ \\
\hline$M-\lambda-X-15-L / 1500$ & $x-x$ & $15 \%$ & $\mathrm{~L} / 1500$ \\
\hline$M-\lambda-X-15-L / 2000$ & $x-x$ & $15 \%$ & $\mathrm{~L} / 2000$ \\
\hline$M-\lambda-X-15-L / 10000$ & $x-x$ & $15 \%$ & $\mathrm{~L} / 10000$ \\
\hline
\end{tabular}

${ }^{1} O$ valor de $\lambda$ na nomenclatura do modelo varia conforme a esbeltez considerada $(45,60,75,90,105,120,135$ e 150$)$.

20 eixo $x$-x é o eixo de maior inércia e o eixo $y$-y é o eixo de menor inércia.

${ }^{3} \mathrm{O}$ valor da tensão residual aqui considerado representa uma porcentagem do valor da resistência ao escoamento do aço.

${ }^{4} \mathrm{~L}$ é o comprimento do pilar. 


\section{RESULTADOS}

\subsection{ANÁLISE DE FLAMBAGEM ELÁSTICA}

Os resultados obtidos após as análises de flambagem elástica são apresentados na Tabela 2. Conforme tratado no item 3.1, estes resultados variam com a esbeltez $(\lambda)$ e não sofrem influência das imperfeições geométricas iniciais e das tensões residuais.

Por meio destes resultados pode-se observar que os valores da carga crítica de flambagem elástica obtida com o auxílio dos modelos computacionais de elementos finitos são próximos dos valores obtidos utilizando-se a equação teórica de Euler. A maior diferença entre eles foi de $5,1 \%$ e ocorreu no modelo $\mathrm{M}-45-\mathrm{X}$, isto é, modelos com esbeltez $(\lambda)$ igual a 45 e flambagem em relação ao eixo de maior inércia $(x-x)$.
De forma geral, pode-se afirmar que os modelos computacionais foram capazes de representar o comportamento de um pilar submetido à flambagem elástica e que as condições de contorno utilizadas conseguiram simular com precisão da condição birrotulada proposta por Euler.

\subsection{ANÁLISE NÃO-LINEAR E INFLUÊNCIA DAS TENSÕES RESIDUAIS}

Os resultados encontrados após as análises não-lineares que avaliaram a influência das tensões residuais são apresentados nas Figura 9 e 10. Nestes gráficos cada ponto representa um modelo analisado, conforme definido na Tabela 1. 0 fator de redução associado à resistência à compressão $(\chi)$ e o índice de esbeltez reduzido $\left(\lambda_{0}\right)$ foram calculados, respectivamente, a partir da carga máxima alcançada pelo modelo numérico e pelo índice de esbeltez $(\lambda)$ deste modelo.

TABELA 2: Carga crítica de flambagem obtida por meio dos modelos numéricos e pela equação analítica proposta por Euler.

\begin{tabular}{|c|c|c|c|c|c|c|c|}
\hline Modelo & $\mathrm{N}_{\mathrm{e}, \text { núm. }}(\mathrm{kN})^{1}$ & $N_{e, \text { analit. }}(k N)^{2}$ & Diferença & Modelo & $\mathrm{N}_{\mathrm{e}, \text { núm. }}(\mathrm{kN})^{1}$ & $N_{e, \text { analit. }}(k N)^{2}$ & Diferença \\
\hline$M-45-X$ & 8577,8 & 9035,7 & $5,1 \%$ & M-45-Y & 8838,3 & 9035,0 & $2,2 \%$ \\
\hline$M-60-X$ & 4944,8 & 5082,6 & $2,7 \%$ & M-60-Y & 5017,3 & 5082,2 & $1,3 \%$ \\
\hline$M-75-X$ & 3201,1 & 3252,9 & $1,6 \%$ & M-75-Y & 3222,5 & 3252,6 & $0,9 \%$ \\
\hline M-90-X & 2236,9 & 2258,9 & $1,0 \%$ & M-90-Y & 2241,9 & 2258,7 & $0,7 \%$ \\
\hline M-105-X & 1649,7 & 1659,6 & $0,6 \%$ & M-105-Y & 1648,8 & 1659,5 & $0,6 \%$ \\
\hline$M-120-X$ & 1266,1 & 1270,7 & $0,4 \%$ & M-120-Y & 1263,1 & 1270,5 & $0,6 \%$ \\
\hline$M-135-X$ & 1002,1 & 1004,0 & $0,2 \%$ & M-135-Y & 998,5 & 1003,9 & $0,5 \%$ \\
\hline$M-150-X$ & 812,7 & 813,2 & $0,1 \%$ & $M-150-Y$ & 809,0 & 813,1 & $0,5 \%$ \\
\hline
\end{tabular}

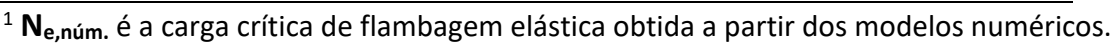

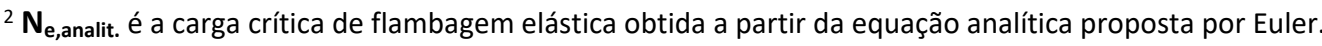




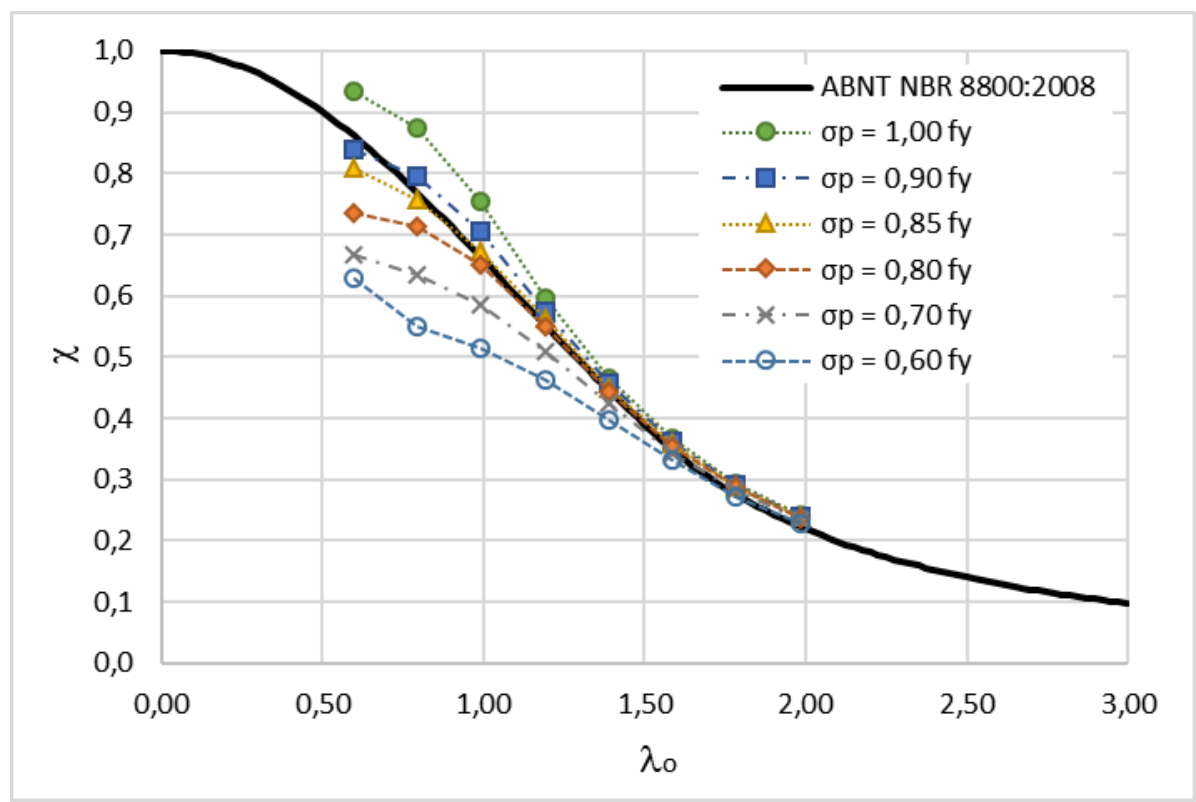

FIGURA 9: Comparação entre a curva $\chi$ versus $\lambda_{\circ}$ prescrita pela ABNT NBR 8800:2008 e as curvas obtidas a partir dos modelos numéricos considerando a flambagem em torno do eixo de maior inércia (eixo $\mathrm{x}-\mathrm{x}$ ).

FONTE: Autores.

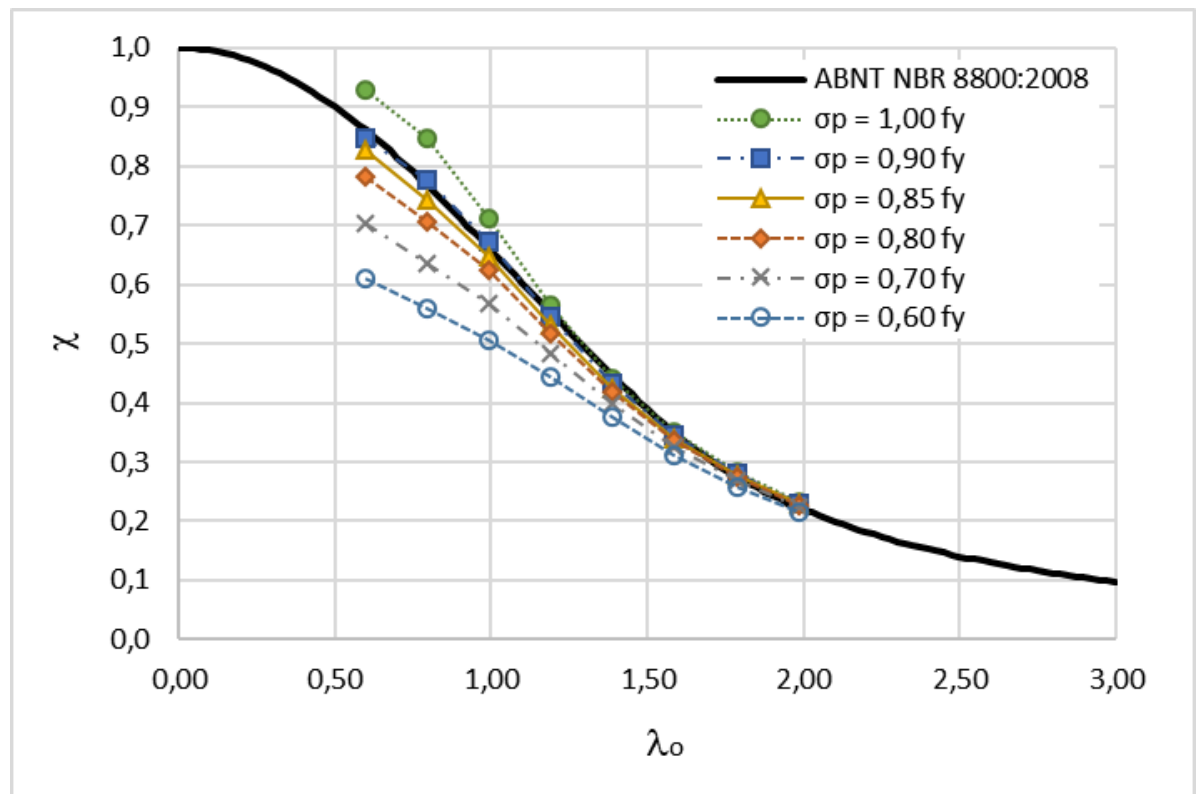

FIGURA 10: Comparação entre a curva $\chi$ versus $\lambda_{\text {。 }}$ prescrita pela ABNT NBR 8800:2008 e as curvas obtidas a partir dos modelos numéricos considerando a flambagem em torno do eixo de menor inércia (eixo y-y).

FONTE: Autores.

Analisando estes resultados observa-se que os modelos com $10 \%$ e $15 \%$ de tensão residual foram os que mais se aproximaram dos valores prescritos pela ABNT NBR 8800:2008. Nota-se também, que a diferença entre os valores obtidos por meio dos modelos numéricos e os valores prescritos pela norma técnica diminuíram à medida que $o$ índice de esbeltez $\left(\lambda_{0}\right)$ aumentou.
Além disso, para valores de esbeltez $\left(\lambda_{0}\right)$ superiores a 1,5 os resultados não apresentaram diferenças significativas, isto é, a tensão residual não provocou influência significativa na capacidade resistente dos modelos numéricos analisados. Estes resultados já eram esperados uma vez que, para valores de esbeltez $\left(\lambda_{0}\right)$ abaixo de 1,5 o pilar está sujeito à flambagem inelástica, 
que é influenciada pelo nível e distribuição das tensões residuais, por outro lado, para valores acima de 1,5 o pilar está sujeito à flambagem elástica, e não sofre influência dessas tensões, como visto no Item 3.1.

Almeida e Lavall (2007), que estudaram a influência das tensões residuais em pilares de aço, obtiveram resultados semelhantes. Segundo estes autores, as tensões residuais diminuem a capacidade resistente dos pilares de aço, principalmente quando o pilar se encontra na região de flambagem inelástica. Por outro lado, quando o pilar se encontra na região de flambagem elástica o efeito das tensões residuais é nulo (ALMEIDA e LAVALL, 2007). Outros autores (JANDERA e MACHACEK, 2014; PILLAR, 2015;
ALPSTEN e TALL, 1970), que também avaliaram a influência das tensões residuais em pilares fabricados em aço, encontraram resultados semelhantes.

A ocorrência de flambagem inelástica e elástica pode ser comprovada analisando as distribuições de tensões na seção crítica do pilar (seção central) quando ele sofre flambagem. $\mathrm{Na}$ Tabela 3 são exibidas as tensões de von Mises obtidas em quatro modelos numéricos isentos de tensões residuais. Nos dois primeiros a flambagem ocorreu em regime inelástico, isto é, ocorreu após parte da seção transversal atingir a tensão de escoamento do aço (345 MPa). Nos dois últimos a flambagem ocorreu em regime elástico, ou seja, antes do aço atingir a tensão de escoamento do aço.

TABELA 3: Tensões de von Mises (MPa) na região central dos pilares sob a atuação da carga que provoca flambagem (modelos isentos de tensões residuais).

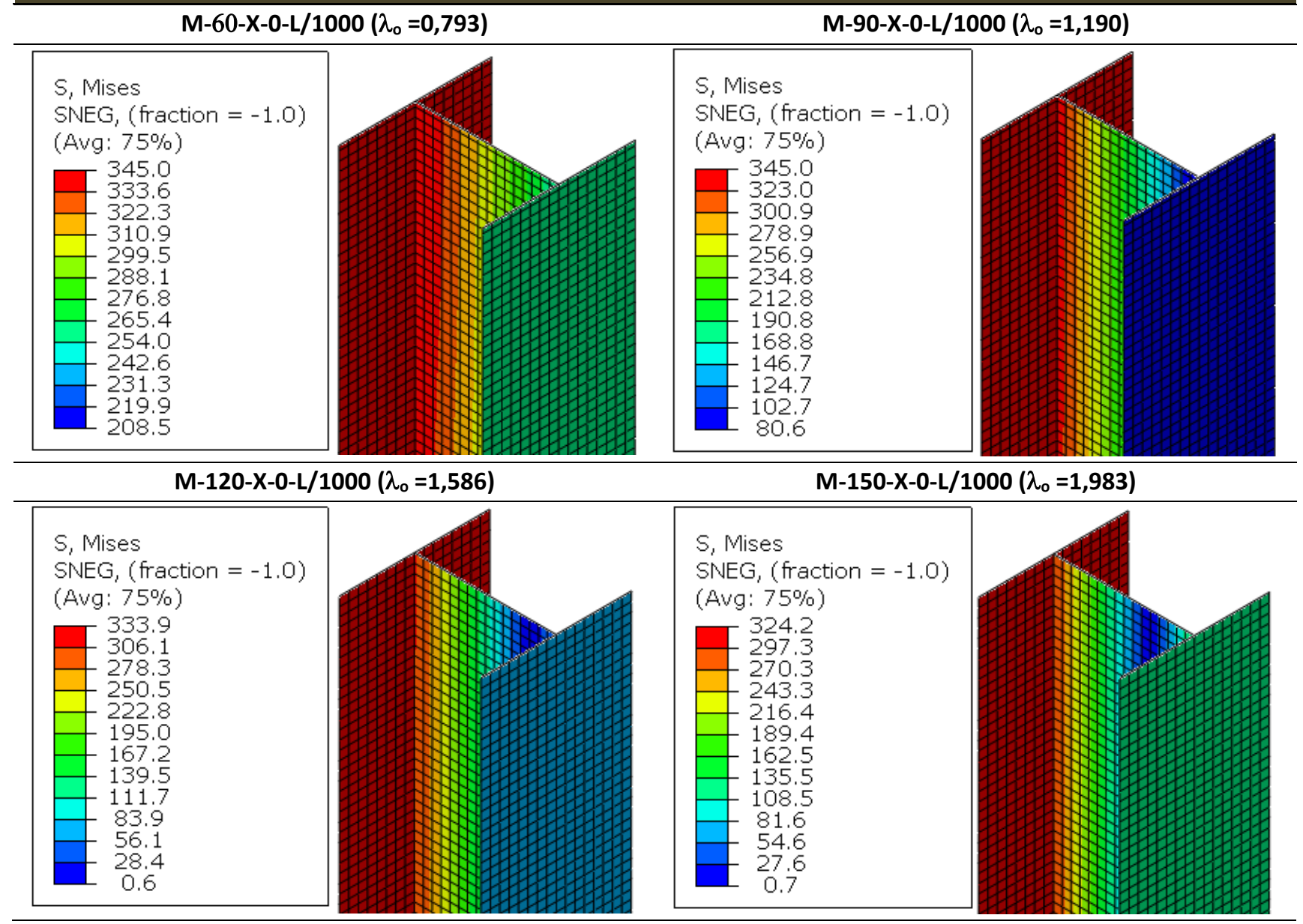


Outro aspecto interessante de ser analisado é o comportamento pós-flambagem do pilar. Nas Figuras 11 e 12 são exibidas as curvas força axial (N) $\times$ deslocamento lateral obtidas a partir dos modelos sem tensões residuais (Figura 11) e dos modelos com $30 \%$ de tensões residuais (Figura 12). Por meio destas curvas observa-se que, em todos os casos, a capacidade resistente à compressão do pilar diminui à medida que o deslocamento lateral aumenta. No entanto, após um grande deslocamento lateral, todas as curvas convergiram para um valor em comum que se aproxima da carga máxima alcançada pelos modelos com esbeltez $(\lambda)$ igual a 150.

De forma geral, as curvas as curvas força axial $(\mathbf{N}) \times$ deslocamento lateral obtidas mostram um comportamento pós-flambagem típico de elementos estruturais de aço submetidos à compressão (GALAMBOS, 1998; PILLAR, 2015).

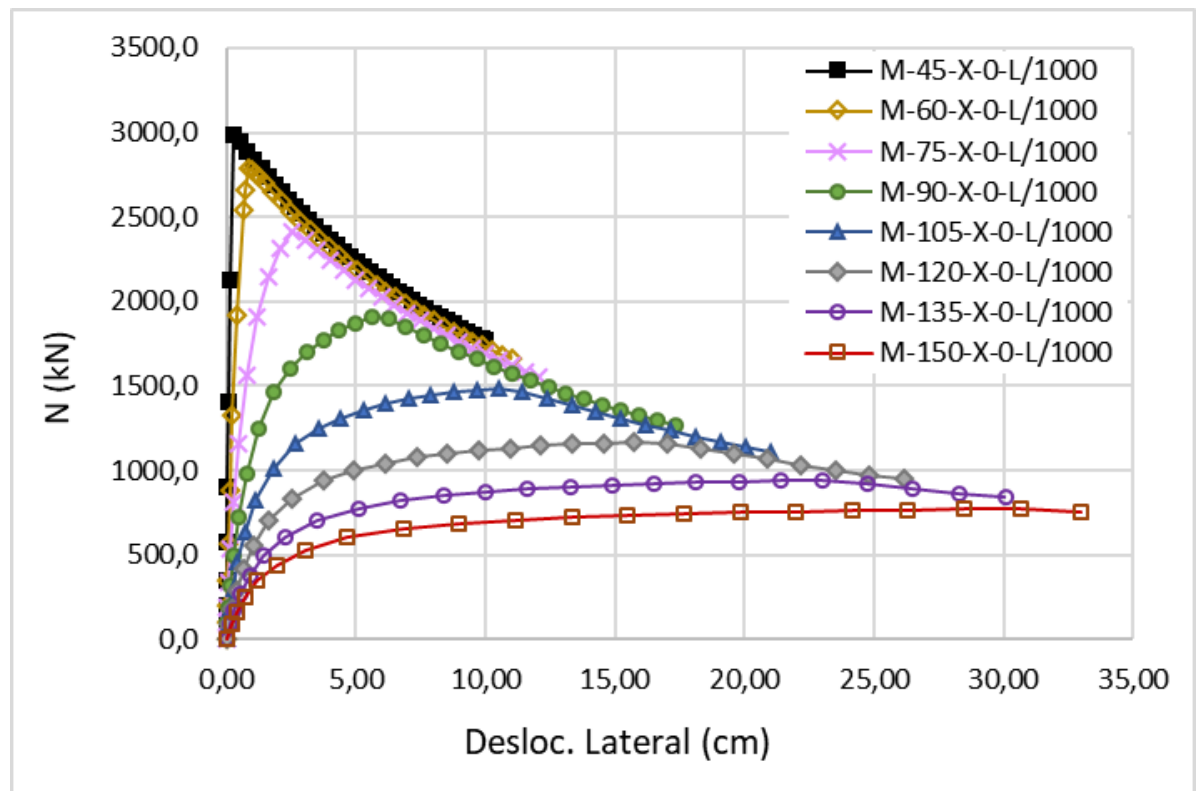

FIGURA 11: Curvas força axial (N) versus deslocamento lateral obtidas a partir dos modelos numéricos isentos de tensões residuais, considerando a flambagem em torno do eixo de menor inércia (eixo y-y).

FONTE: Autores.

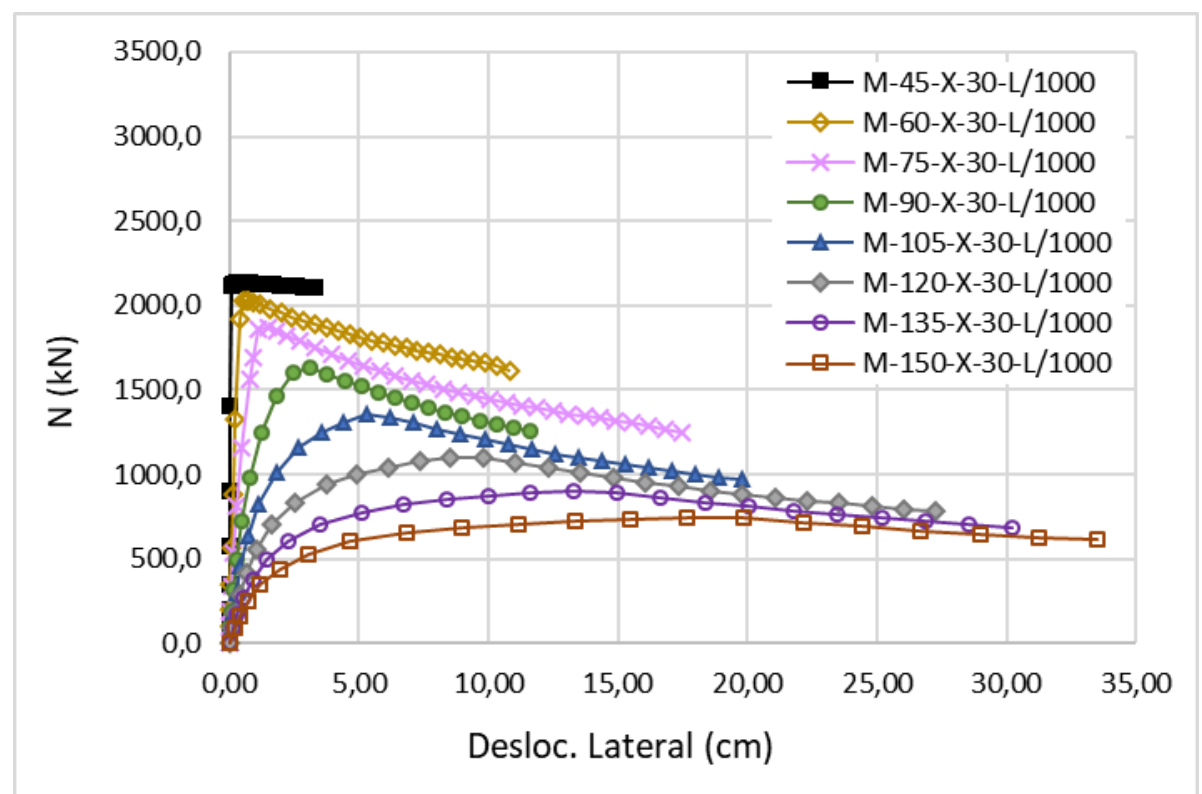

FIGURA 12: Curvas força axial (N) versus deslocamento lateral obtidas a partir dos modelos numéricos com $30 \%$ de tensões residuais, considerando a flambagem em torno do eixo de menor inércia (eixo y-y).

FONTE: Autores. 


\subsection{ANÁLISE NÃO-LINEAR E INFLUÊNCIA DAS} IMPERFEIÇÕES GEOMÉTRICAS

Os resultados obtidos após as análises não-lineares que avaliaram a influência das imperfeições geométricas são exibidos na Figura 13. Novamente, nestes gráficos cada ponto representa um modelo analisado, conforme definido na Tabela 1.

Analisando estes resultados nota-se que os modelos com imperfeições de L/1000 e L/1500 foram os que mais se aproximaram dos valores prescritos pela NBR 8800 (ABNT 2008). Os modelos com maiores imperfeições geométricas apresentaram as menores cargas resistentes e os modelos com menores imperfeições as maiores cargas resistentes. Além disso, diferentemente dos resultados obtidos com as análises relacionadas às tensões residuais, as imperfeições geométricas influenciaram o comportamento dos pilares em regime de flambagem inelástica $\left(\lambda_{0} \leq 1,5\right)$ e elástica $\left(\lambda_{0}>1,5\right)$.

\section{CONCLUSÕES}

Este trabalho teve como objetivo simular computacionalmente 0 comportamento estrutural de pilares de aço submetidos à compressão axial e avaliar a influência das imperfeições de material (tensões residuais) e geométricas sobre este comportamento. Desta forma, com o auxílio do software Abaqus (DASSAULT SYSTÈMES, 2012), desenvolveram-se modelos numéricos de elementos finitos, que foram validados comparando os resultados numéricos obtidos com os resultados analíticos encontrados a partir da equação de flambagem elástica de Euler (Eq. [6]) e pela curva de flambagem prescrita pela NBR 8800 (ABNT, 2008) (Figura 4).

As análises realizadas para avaliar a influência das imperfeições de material mostraram que os modelos com $10 \%$ e $15 \%$ de tensão residual foram os que mais se aproximaram dos valores prescritos pela ABNT NBR 8800:2008. Além disso, para valores de esbeltez $\left(\lambda_{0}\right)$ superiores a 1,5 , regime de flambagem elástica, os resultados não apresentaram diferenças significativas, ou seja, a tensão residual não provocou influência significativa sobre a capacidade resistente destes modelos.

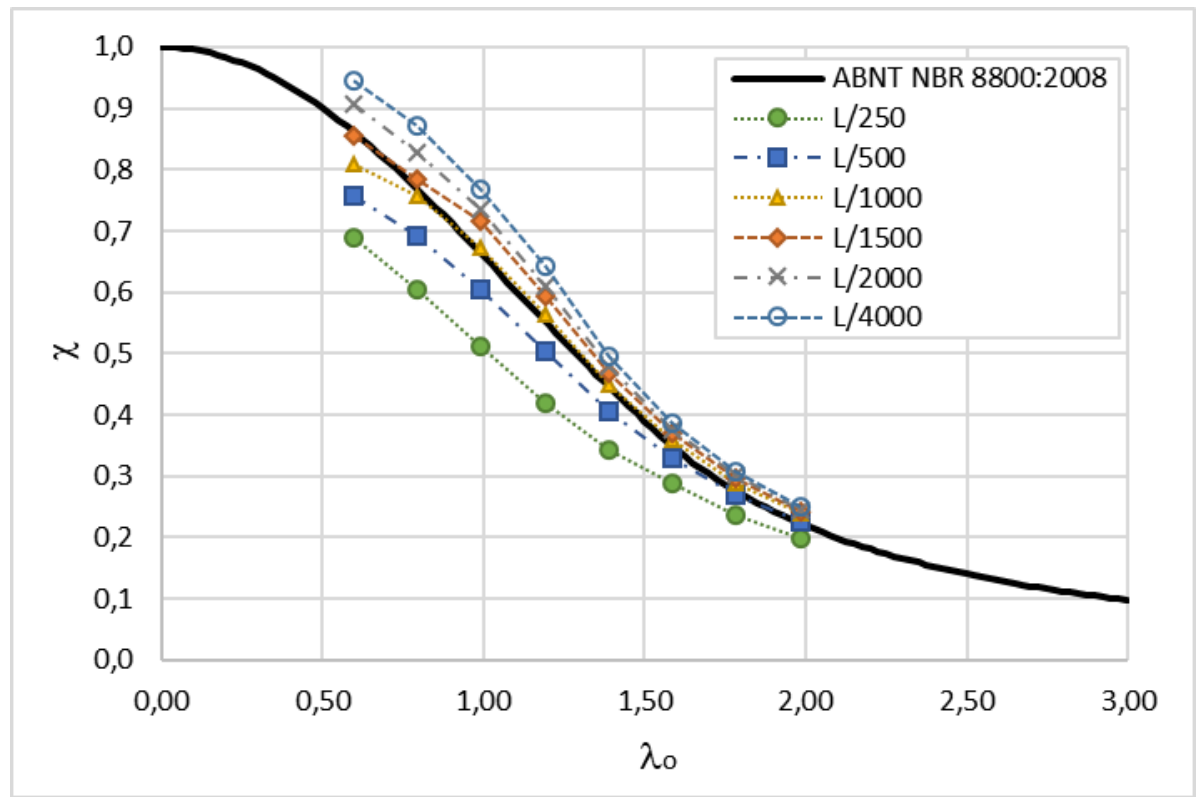

FIGURA 13: Comparação entre a curva $\chi$ versus $\lambda_{0}$ prescrita pela ABNT NBR 8800:2008 e as curvas obtidas a partir dos modelos numéricos considerando a flambagem em torno do eixo de maior inércia (eixo x-x).

FONTE: Autores. 
Por meio das análises realizadas para avaliar a influência das imperfeições geométricas observou-se que os modelos com imperfeições de $\mathrm{L} / 1000$ e $\mathrm{L} / 1500$ foram os que mais se aproximaram dos valores prescritos pela ABNT NBR 8800:2008 e que, diferentemente dos resultados obtidos com as análises relacionadas às tensões residuais, as imperfeições geométricas influenciaram o comportamento dos pilares em regime de flambagem inelástica $\left(\lambda_{0} \leq 1,5\right)$ e elástica $\left(\lambda_{0}>1,5\right)$.

De forma geral, as estratégias adotadas para o desenvolvimento e análise dos modelos computacionais de elementos finitos permitiram simular e avaliar o comportamento estrutural de pilares de aço com diferentes níveis de tensões residuais e imperfeições geométricas, o que pode contribuir para futuras pesquisas que estejam relacionadas com o comportamento de pilares de aço, flambagem em regime elástico e inelástico, influência das tensões residuais e imperfeições geométricas e simulação computacional de elementos estruturais via método dos elementos finitos (MEF).

\section{AGRADECIMENTOS}

Os autores agradecem à Universidade Federal de Viçosa (UFV) pela infraestrutura disponibilizada para realização da pesquisa.

\section{REFERÊNCIAS BIBLIOGRÁFICAS}

ALMEIDA, A. C. B.; LAVALL, A. C. C. Influência das tensões residuais na resistência de pilares de aço considerando a análise avançada com plasticidade distribuída. REM: Revista Escola de Minas, v. 60, n. 2, p.391-399, jun. 2007. http://dx.doi.org/10.1590/s037044672007000200021.

ALMEIDA, P.H.F. Estudo Numérico de um Dispositivo de Transferência de Cargas em Pilares Mistos Tubulares Preenchidos com Concreto. Dissertação de mestrado em Engenharia de Estruturas. Universidade Federal de Minas Gerais. Belo Horizonte, 2012.
ASSOCIAÇÃO BRASILEIRA DE NORMAS TÉCNICAS, NBR 8800: Projeto de Estruturas de Aço e de Estruturas Mistas de Aço e Concreto de Edifícios. Rio de Janeiro, 2008.

CARDOSO, H. S. Estudo Teórico-Experimental de Parafusos Utilizados como Dispositivos de Transferência de Carga em Pilares Mistos Tubulares Preenchidos com Concreto. Dissertação de mestrado em Engenharia de Estruturas. Universidade Federal de Minas Gerais. Belo Horizonte, 2014.

DASSAULT SYSTÈMES. Abaqus 6.12. Providence, RI, USA. 2012 (Software).

DUTRA, C.M. Estudo do Comportamento Estrutural do Conector Crestbond Considerando Variações Geométricas e Mecânicas. Dissertação de mestrado em Engenharia Civil. Universidade Federal de Viçosa, Viçosa. 2014.

FAKURY, R. H. Dimensionamento Básico de Elementos de Estruturas de Aço. 3a Ed. UFMG (Apostila). Belo Horizonte, 2009.

FAKURY, R. H.; SILVA, A. L. R. C.; CALDAS, R. B. Dimensionamento de Elementos Estruturais de Aço e Misto de Aço e Concreto. 1a Ed. Pearson Education do Brasil. São Paulo, 2016. 496 p.

GALAMBOS, T. V. Guide to Stability Design Criteria for Metal Structures. 5a Ed. John Wiley \& Sons, inc. New York, 1998. 911 p.

HIBBELER, R. C. Resistência dos Materiais. 7ạ Ed. Pearson Prentice Hall. São Paulo, 2010. 642 p.

JANDERA, M.; MACHACEK, J.. Residual stress influence on material properties and column behaviour of stainless steel SHS. Thin-walled Structures, v. 83, p.1218, out. 2014. Elsevier BV. http://dx.doi.org/10.1016/j.tws.2014.03.013.

PILLAR, R. V. Influence of Residual Stresses on the Strength of Steel Rectangular Hollow Sections Columns. Dissertação de mestrado em Engenharia Civil. COPPE. Universidade Federal do Rio de Janeiro. Rio de Janeiro, 2015.

QUEIROZ, G. Elementos das Estruturas de Aço. 1ạ Ed. Edição Particular. Belo Horizonte, 1986. 455 p.

TIMOSHENKO, S. P.; GERE, J. M. Theory of Elastic Stability. 2a Ed. Engineering Societies Monographs. McGraw-Hill. New York, 1961. 